\title{
Advancing the Circular Economy in Public Sector Organisations: Employees' Perspectives on Practices
}

\author{
Natacha Klein ${ }^{1}$ (D) - Tomás B. $\operatorname{Ramos}^{1}$ (D) Pauline Deutz ${ }^{2}$ (D) \\ Received: 18 December 2020 / Accepted: 6 April 2021 / Published online: 28 April 2021 \\ (C) The Author(s) 2021, corrected publication 2021
}

\begin{abstract}
Circular economy (CE) is a concept that is gaining attention as an approach to help accelerate the transition towards sustainability. Research has focused on the adoption of CE practices in the business sector while the adoption within public sector organisations has been relatively overlooked. Examining CE adoption in the public sector through the perceptive of employees is crucial because of their expertise in the organisation where they work. The main aim of this study is to identify what public employees perceive as suitable $\mathrm{CE}$ practices for their organisations and their critical role in implementation. As the adoption of $\mathrm{CE}$ practices is influenced by social and material configurations, this research has taken a case study approach, focused on the Portuguese Central Public Administration. Semi-structured interviews were conducted with public employees working on $\mathrm{CE}$ and sustainability issues, and a complementary analysis was undertaken of governmental reports and legislative documents. The results show that public employees view the existence and potential of CE practices mainly in the area of public procurement but also in resource efficiency and optimisation, dematerialisation and in practices related to the R-hierarchy including reduce and reuse. Both technical-oriented practices aimed to achieve traditional resource efficiency, and human-centred practices targeted at reducing consumption and sharing resources have been identified. This research provides insights into how a specific group of stakeholders envisions CE activities for their sector. Identification of practices for central public sector has the potential to assist decisionmakers in the process of defining priorities for CE planning, implementation and monitoring. This study focusing on CE practices in central public sector organisations contributes to the calls for an inclusion of human/socially-based practices centred around consumption reduction, sharing and dematerialisation activities to enhance the transformative and innovative potential of CE.
\end{abstract}

Keywords Circular economy · Practices · Implementation · Public sector · Employees · Organisations

Natacha Klein

n.klein@ campus.fct.unl.pt

Extended author information available on the last page of the article 


\section{Introduction}

The circular economy (CE) is widely presented as a tool to address the challenges of our current unsustainable production and consumption model and therefore as a way to accelerate progress towards sustainability $[1,2]$. CE scholars suggest that the implementation of $\mathrm{CE}$ is taking place and can be observed at three different levels: macro, meso and micro level [3, 4]. The majority of the studies researching on $\mathrm{CE}$ at the micro level of individual organisations have focused on private companies, whereas the public sector seems to have been considered mostly at the macro level of policies and regulations as a result of public policies implementation in China and Europe [5]. The interest of private companies to adopt CE principles might be due to the fact that $\mathrm{CE}$ has been depicted as having economic advantages as well as positive environmental impacts by several organisations [6]. Comparatively, research on the adoption of circularity within Public Sector Organisations (PSOs) has been overlooked [7, 8]. This lack of spotlight on the public sector at organisational level is probably due to the idea that the public sector is mostly seen as a driver to accelerate and scale up the implementation of CE in other sectors via governmental actions $[9,10]$.

The public sector is a major contributor in the economic system as a significant employer, purchaser of goods and services and as a regulator and policy-maker at national, regional and local level [11]. The purchasing power of the public sector through Public Procurement (PP) accounts for an average of $12 \%$ of gross domestic product (GDP) in countries of the Organisation for Economic Co-Operation and Development (OECD) [12]. Moreover, general government expenditure stood at 46.7\% of GDP in 2018 for the European Union's 27 countries [13]. The public sector is also generally seen as responsible for being a role model for society [14], to serve as an example of good practice especially at national level $[15,16]$. Central/ national PSOs are the ones designing the policies, setting the priorities for the sustainability and CE transition and its implementation within a country at all levels. Therefore, given the size and influence of the public sector, it is important for organisations pertaining to that sector to consider their contribution to CE models and approaches and to be an integral part of the transition towards sustainability [8]. The value for PSOs to adopt organisational CE practices is situated in its pragmatical potential to reach greater levels of sustainability [7, 17] by bringing a different approach from previous sustainable management efforts in PSOs.

A fundamental element to investigate concerns the practices related to $\mathrm{CE}$ as they unfold within a socio-material setting such as PSOs. Examining practices is crucial in the context of the $\mathrm{CE}$ transition because changes in practices at individual and organisational level are needed to bring about transformative and fundamental changes of production systems and consumption patterns [18]. Employees are the stakeholder group that 'constitute' organisations [19]. They are the individuals that are using the resources to perform actions and operate tasks; they are developing habits, patterns of behaviours and practices at organisational level. In this respect, public employees possess a privileged relationship to and experience of public sector organisational settings and operations [20], which is essential to capture. Understanding the employees' perception of the adoption of CE practices within their own organisation will provide insights into how central PSOs as organisational systems can implement circularity and contribute to a circular society. Moreover, understanding the role and view of employees in the adaptation of CE principles into practice in organisations is a topic that has been little dealt with so far in any setting [21]. Therefore, this research will shed light on the role of the public sector as a role model, as a vital actor in the economy that also holds the status of buyer, consumer, users of goods and services in addition to policy maker. 
Considering the above-mentioned lack of research on the $\mathrm{CE}$ principles and practices adapted to the public sector at the organisational level, the main aim of this research is to identify what public sector employees perceive as suitable CE practices for central PSOs. CE practices can be identified by studying the specific social and material configurations [22] of a central public administration. Therefore, a case study approach has been chosen in which public sector employees involved in sustainability-related work at central level in Portugal have been interviewed, and governmental documents have been analysed.

The remainder of this article will, in the next section, provide the research background on CE practices in the public sector at organisational level. Thereafter, "Research Methods" will present the case study of the Portuguese Central Public Administration (PCPA) and explain the methods chosen to identify the range of relevant $\mathrm{CE}$ practices. The results and discussion will then be presented and followed by concluding remarks.

\section{Overview of Circular Economy Implementation in Public Sector Organisations}

The concept of CE practices has been used in many different ways and circumstances in the literature so far, as well as words and concepts implying similar meaning such as $\mathrm{CE}$ initiatives, strategies, activities, actions, measures, among others. For this article, CE practices are characterised as a set of actions and behaviours shared and carried out by individuals in spatially and temporally situated socio-material setting that can be observed within organisations, and in the scope of this article, within central PSOs. This working definition is inspired by a practice theory perspective of CE put forward by previous studies arguing for a more nuanced understanding of CE operationalisation where practices cannot be separated from their material, spatial and social context [18]. The most commonly used and frequently mentioned group of $\mathrm{CE}$ practices appears to be the $3 \mathrm{Rs}$ principles which refer to reduce, reuse and recycle [17] and others, which can be ranked from the most to the least desirable for a closed loop of material and energy flows [14]. These Rs principles including other Rs such as repair are often cited as the possible approaches to implement CE in practice [23, 24].

Research into CE practices in the public sector has focused mainly on studying the integration of $\mathrm{CE}$ in the areas of $\mathrm{PP}$, internal operations and processes and public service delivery [8]. PP is the area where the majority of the research has been undertaken. Indeed Circular Public Procurement (CPP) refers to the incorporation of CE principles, including Rs principles, in Green Public Procurement (GPP) or Sustainable Public Procurement (SPP) processes [25-27]. GPP and SPP correspond to the incorporation of environmental and broader sustainability (including social) aspects in the purchasing decisions of governments respectively $[28,29]$. The most applied and researched CE practices in PP procedures seem to be the integration of criteria for remanufactured products (e.g. remanufactured computers and office furniture) and for recycled content in products (e.g. recycled material in the construction of public buildings) [8]. Other examples of CPP practices have included specifications for possibility of disassembly to enable the reuse of products and award criteria for the use of biofuels in public buses [12, 30, 31]. Consequently, if carefully designed and developed, CPP is a crucial tool for public administrations to reach greater levels of organisational sustainability and to use as a leverage point to promote CE practices and implementation at societal level, in companies and supply chains $[32,33]$. 
Besides the integration of CE in PP processes, the internal operations and day-to-day work processes of PSOs has been researched for CE implementation. Examples given revolve around Rs practices and include for instance the provision of reusable mugs to employees, the use of online platforms for the reuse of equipment and furniture, the recycling of used work uniforms but also circular approaches to lighting, heating, water and space use in buildings [34-37]. Energy and resource efficiency initiatives linked to the optimisation of buildings seem to represent a significant part of the CE implementation in those studies. Although it is stated that building upgrades are often only pursued for financial reasons [36], practices aiming towards the reduced and optimised use of energy, water and space in buildings are nonetheless viewed as a valid starting point for a transition from linearity to circularity in organisations [34]. Adopting Environmental Management Systems (EMS) has also been associated as a CE practice because those standards include the implementation of a range of actions aiming towards energy and resource efficiency and optimisation [38]. EMSs such as the EU EcoManagement and Audit Scheme (EMAS) and ISO:14001 standards enable an organisation to manage, monitor its environmental impacts, and improve its environmental performance [39], and the implementation of CE practices in organisations, whether public or private, has been shown to be positively impacted by an EMS certification [40].

Nevertheless, circular initiatives implemented so far are incremental and limited in scope because they are oriented towards emission reduction, energy and resource efficiency and mere waste reduction which still lies in a linear thinking frame $[34,36]$. Numerous scholars have highlighted that the current approaches to the implementation of CE emanate mostly from the field of Industrial Ecology (IE) [41, 42]. IE is designated as the study of material and energy flows in industrial ecosystems which applies ecological principles inspired from natural ecosystems to treat industrial waste [42-44]. Although technological and engineering-based IE-inspired tools such as the use of Life Cycle Assessment (LCA) are a necessary step towards CE implementation [41], they are not sufficient to implement the systemic transformation of production and consumption systems envisaged by some understandings of the CE [17]. The present article therefore responds to the point made by Hobson that for a transformational implementation of CE in organisations, "a CE is deemed to necessitate that all aspects of production-consumption be open to scrutiny and potentially recalibrated" [41 p.92]. In the present research, those aspects include the above-mentioned technical and engineering aspects of resource efficiency and R-based practices and the social and human aspects of producing and especially consuming resources and services.

The social practices pointed out in the CE literature as having transformational potential include ideas from the sharing economy and collaborative consumption pertaining to notions of diverse economies (e.g. gift economy), de-growth and post-capitalism that are deeply linked to norms, places and everyday practices [45]. These practices are then highlighting the importance of human-centred issues in the implementation of CE such as trust, empowerment, cooperation and inclusive participation $[18,46]$. Practices related to the sharing economy are said to have the potential to address the current weak social dimension of CE [47]. For instance, Ganapati and Reddick [48] have demonstrated that the opportunities of the sharing economy for the public sector as a user lies in changing the procurement practices from buying assets to renting assets from peer organisations and in using digital platforms to enable peer-topeer sharing of assets so that they are used at capacity (usually equipment, vehicles and spaces). Practices related to the use and consumption aspects of material resources such as the act of sharing should also be considered. Sharing practices are associated to the CE principle of reuse and 'stewardship over ownership' which tend to be socio-digital in nature, driven by 
digital technologies with most literature focused on the mobility sector (car sharing and ride sharing platforms) and the housing and building sector with examples of business digital platforms such as Airbnb [49]. Moreover, according to the report conducted by the Ellen MacArthur Foundation (EMF) [50] presenting their ReSOLVE framework, the highestpriority action areas for the public administration sector are share (sharing the use of, reusing and repairing products) and virtualise (dematerialising resource use by delivering utility virtually) thus highlighting the relevance of sharing as a suitable $\mathrm{CE}$ dimension for the public sector.

Furthermore, dematerialisation, virtualisation and digitalisation are terms that refer to various practices under a CE. The World Business Council on Sustainable Development (WBCSD) has defined in their CE Practitioner Guide that dematerialisation includes resource efficiency and optimisation practices, digitising the purchase of products and encouraging selling products as a service [51]. Although dematerialisation has been acknowledged as an enabler of the $\mathrm{CE}$ expecting to promote more efficient processes in organisations, waste minimisation, longer life for products and transaction cost minimisation [52], little research and few case studies have been undertaken to explore the impacts of digitalisation for a $\mathrm{CE}$ in practice [49]. The literature so far warns about issues related to the material use in the manufacturing of digital hardware and risk of rebound effects related to the consumption of efficient digital technologies [53, 54]. Some studies have looked at the environmental impacts of dematerialisation processes in public administration using LCA, for instance to demonstrate that using Information and Communication Technology (ICT) has lower environmental impacts than traditional paper documentation management [53], but dematerialisation was not labelled under the CE umbrella by the authors.

This section has demonstrated that previous studies have focused on specific CE-related practices in the public sector but given little attention to integrated analysis of several CEbased practices and to social and human aspects of a $\mathrm{CE}$ transition. This research provides a holistic overview of how the implementation of CE activities in central PSOs is perceived by the people involved in the process. $\mathrm{CE}$ is seen as a set of practices pertaining to all aspects of a circular model including the material, technical, human and social aspects. Consequently, based on the demonstrated multidimensional nature of $\mathrm{CE}$ and its transformative potential residing in $\mathrm{CE}$ practices, for the purpose of this article, we define $\mathrm{CE}$ in an organisational public sector context as a model of procuring/purchasing - consumption/use - after use management in which resources, products and services are purchased, consumed or used and managed after use within a socio-material/technical system (a central PSO) involving individuals (e.g. public employees, suppliers, public sector constituents) that are carrying out practices that are contributing to the CE. This study is collecting new empirical insights from employees working in central PSOs as they are the most qualified individuals to interrogate on the suitable organisational CE practices.

\section{Research Methods}

\section{Case Study: Portuguese Central Public Administration}

As this study intends to capture insights from public employees on CE practices suitable for the specific organisational, social and material context of central PSOs, an appropriate methodological approach for such empirical study is a case study approach. The Portuguese 
Central Public Administration (PCPA) has been selected as a case for identifying CE practices in central PSOs because the Portuguese central government has demonstrated political commitment as a policy-maker for the $\mathrm{CE}$ and its implementation at national scale. Indeed, the National Action Plan for Circular Economy 2017-2020 (PAEC) was adopted by the Portuguese Council of Ministers in 2017. To ensure the implementation of the PAEC, the Portuguese government has established an inter-ministerial group that includes technical and administrative level representatives appointed by the ministers for foreign affairs, science, technology and higher education, health, planning, economy, environment, agriculture, forestry and maritime affairs. They are coordinated by representatives appointed by the ministers for the economy and the environment [55]. This inter-ministerial group plays a key role in spreading CE principles in government policies, promoting and facilitating the execution of the PAEC's guidelines across policy areas, governmental levels and sectors in Portugal [55]. Additionally, the public sector in Portugal makes an important case as it represents a significant part of the economy with a total general government employment corresponding to $14.4 \%$ of the total labour force of the country in 2017 [56]. Finally, the central government share of general government employment accounts for $76.17 \%$ in 2017 , which highlights the fact the Portuguese public administration has high degrees of centralisation [57].

\section{Interviews}

Semi-structured interviewing was chosen as the data collection method for this qualitative study as it enables the research to have the flexibility to explore the complexity of the topic [58]. Therefore, in order to identify suitable CE practices from the perspective of public employees in Portugal, 14 interviews were conducted with employees involved in sustainability-related work from different departments of organisations belonging to the PCPA between July and September 2019.

An initial series of visits and meetings had been undertaken preliminarily with relevant contacts to get a sense of the organisational structure of the PCPA work on $\mathrm{CE}$ and to identify the relevant organisations to target for the interviews. The sampling strategy was made in two stages. The first sampling process was done in collaboration with a key contact person responsible for the coordination of the inter-ministerial group. This person was asked to select in a purposive manner the first sample of interviewees (8) based on criteria of relevance and knowledge as recommended by Denscombe [59]: (i) the interviewee should be relevant to the topic of CE practices in central PSOs and therefore should be working in departments and units dealing with CE-related, environmental or sustainability issues; (ii) the interviewees should be selected according to the relevant knowledge they have regarding $\mathrm{CE}$ and sustainability issues [60]. The purposive sampling was made through the inter-ministerial group as the members of the group are the people most likely to have the experience and expertise to provide quality information and valuable insights on the research topic [59].

The interviewees for the second round (6) were selected using a snowball sampling method [61] as while conducting the first round of the interviews, each interviewee was asked to indicate suitable additional participants with relevant experience and knowledge in CE within the PCPA. In the end, the interviewees were from seven different ministries in positions ranging from environmental engineer, head of sustainability divisions or departments to political advisor on sustainability issues. Half of the interviews were conducted with employees from the Ministry of Environment and Climate Action. Such 
proportions were assumed on purpose as one of the sampling criteria was to interview employees working on environmental or sustainability-related issues. See Table 1 for an overview of the different organisations to which the interviewees belong.

The interviews utilised a protocol for semi-structured interviews, as recommended by Creswell [62]. The protocol was divided in three distinctive parts to cover the relevant topics for this research: (i) introductory questions; (ii) CE general questions; (iii) $\mathrm{CE}$ practices questions (see Appendix 1). Follow-up questions were asked for further clarification when necessary. All the interviews were conducted in English, lasted between 40 and 90 min and were recorded with explicit agreement from all the interviewees. The requirement to speak English did not affect the selection of interviewees, neither in the purposive nor the snowball sampling process as employees working in the PCPA generally have a very good level of English. The interviews followed the required ethical procedures ensuring informed consent, by clearly stating the purpose and use of the data collected, ensuring confidentiality and anonymity of the interviewees as well as the potential risks [63]. The interviews were subsequently transcribed and then coded using the NVivo software in order to identify themes/sub-categories as well as relevant statements coming up in the conversations $[62,63]$. By identifying and analysing themes and categories emerging from the content of the interviews, this study is using the method of content analysis [59]. Some 'analytical categories' were first established based on the background literature on $\mathrm{CE}$, and otherwise 'grounded categories' have been created inductively as discovered while coding the text [63]. The authors have taken into account, in the interpretation and analysis of the results, the potential varying $\mathrm{CE}$ knowledge base and bias of the interviewees to achieve a high level of validity for the interviews [62]. Moreover, due to the unavailability or non-response to interview invitations, certain ministries are not represented in the final interview sample, and this has been acknowledged as a limitation of the research. Other interview limitations in terms of reliability, forms of bias of both the interviewers and the interviewees, cultural and language issues as well as validity/credibility issues have been considered and mitigated accordingly [58].

Table 1 Overview of the interviewees' characteristics

\begin{tabular}{|c|c|c|}
\hline Interviewees' organisation & Corresponding Ministry & $\begin{array}{l}\text { No. of } \\
\text { interviews }\end{array}$ \\
\hline Portuguese Environmental Agency & $\begin{array}{l}\text { Ministry of Environment } \\
\text { and Climate Action }\end{array}$ & 5 \\
\hline Secretariat-General for Environment & $\begin{array}{l}\text { Ministry of Environment } \\
\text { and Climate Action }\end{array}$ & 1 \\
\hline Office of the Secretary of State for Environment & $\begin{array}{l}\text { Ministry of Environment } \\
\text { and Climate Action }\end{array}$ & 1 \\
\hline Directorate-General for Economic Activities & Ministry of Economy & 1 \\
\hline Statistics Portugal & Ministry of Economy & 1 \\
\hline Planning, Policy and General Administration Office & Ministry of Agriculture & 1 \\
\hline Directorate-General for National Defence Resources & Ministry of National Defence & 1 \\
\hline Central Administration of the Health System & Ministry of Health & 1 \\
\hline $\begin{array}{l}\text { Directorate-General for Natural Resources, Safety and } \\
\text { Maritime Services }\end{array}$ & Ministry of Maritime Affairs & 1 \\
\hline Entity of Shared Services for Public Administration & $\begin{array}{l}\text { Presidency of the Council of } \\
\text { Ministers }\end{array}$ & 1 \\
\hline
\end{tabular}




\section{Documents and Reports Analysis}

Secondary data in the form of mostly environment- or sustainability-related governmental reports and legislative documents produced by the PCPA have also been collected for analysis. This complementary source of data has been integrated in the analysis as the selected documents have been mentioned by the interviewees and therefore have been evaluated as highly relevant material providing valuable insights into the mentioned $\mathrm{CE}$ practices. Adding a second data source allow for the triangulation of information obtained from the interviews thus adding to the validity of the results [62]. As a result, four governmental reports and two legislative documents have been collected from the organisations' websites or provided directly by the interviewees (see the detailed list in Appendix 2). A qualitative content analysis [59] was carried out by inductively screening the reports and documents for relevant $\mathrm{CE}$ practices to complement the codes and categories from the interviews. Limitations similar to those from the interviews were recognized in addition to limitations regarding the restricted scope of this secondary data sample. The documents and reports are considered as complements to the interviewees' input, and therefore, a collection and analysis of a larger number of reports and documents was not undertaken for the present study.

\section{Results and Discussion}

This section introduces the identified CE practices for central PSOs according to the interviewed employees and as mentioned in the documents and reports. The practices have been divided into four categories based on dimensions of CE practices found in the literature (see Table 2 for an overview of the CE practices grouped by category). Within the set of CE practices, both technical-oriented practices aimed to achieve traditional resource efficiency and human-centred practices targeted for consumption reduction, sharing and dematerialisation activities have been identified. This range of $\mathrm{CE}$ practices highlights that the interviewees and the public administration seem to be aware of the transformative potential of introducing CE practices addressing consumption behaviours in day-to-day operations alongside the traditional technical resource efficiency-oriented practices which has been stressed by previous literature [22, 46]. These findings exhibit that PSOs are different from manufacturing, producer-oriented organisations in that most of the $\mathrm{CE}$ practices identified are linked to a 'consumeroriented' perspective as opposed to a 'producer' perspective [14] as the next subsections will demonstrate.

The results show that several interviewees' awareness and attention were on CE practices that are linked to PP, with 12 practices related to the integration of circular criteria and specifications in PP processes. This is consistent with the current research and practice that also looks into PP for CE implementation in the public sector as a key practice [8]. Thereafter, R-based and sharing practices were the most discussed as well as dematerialisation practices, and followed by resource efficiency practices with six practices in this last category. Finally, bearing in mind Klein et al.'s [8] organisational CE framework of a PSO, the identified CE practices are found to impact on the internal processes and operations with the optimizing, Rsbased, sharing and dematerialising practices and on the area of PP with a collection of CPPfocused practices. 
Table 2 CE practices identified by one or more of the 14 interviewees and/or mentioned in the documents and reports collected. Practices have been aggregated into categories taken from the literature

\begin{tabular}{ll}
\hline CE practices categories & $\begin{array}{l}\text { Identified } \\
\text { practices (no.) }\end{array}$ \\
\hline Resource Efficiency and Optimisation & 6 \\
Rs-based and Sharing Practices & 7 \\
Dematerialisation and Virtualisation & 7 \\
Circular Public Procurement & 12 \\
Total & 32 \\
\hline
\end{tabular}

\section{General Perception of CE Implementation in Central PSOs}

The majority of the interviewees asserted that $\mathrm{CE}$ has great potential for their organisation and for the public sector in general, considering the size of the central government covering different locations but also mentioning potential for better performance and efficiency, financial savings and for collaboration and social cohesion. For some of them, the implementation of CE essentially revolves around changing people's mindset, behaviour and culture around consumption and resource use in PSOs. For instance, an interviewee stated that 'because we are a culture of consuming, consuming, consuming; why am I going to reuse the same clothes, the same paper, the same pen? Why? We are not used to this culture. I think this is the most difficult aspect'. A few interviewees emphasized the importance of introducing small changes in the organisation explaining that 'it would be easier to incorporate these small examples so that little by little both the suppliers do it and the public entities get used to these small changes. (...) Why do I believe it's better to go little by little? Because changing culture is difficult'. Conversely, drastic measures run the risk of discouraging stakeholders and might be counterproductive. In CE literature, Hobson also pointed out the transformative potential of acting on daily operations and processes by stating that there is 'potential of everyday lives to be transformed through seemingly minor but actually profound conceptual shifts' [45 p. 21].

\section{Resource Efficiency and Optimisation Practices}

The interviewees mentioned the relevance of practices focusing on optimising the use of resources especially in the context of buildings and infrastructure for central PSOs and even more specifically in terms of energy and resource efficiency (see Table 3). During the interviews, the optimisation practices for central public buildings were often the first practices to be mentioned, highlighting the importance of resource efficiency for the interviewed employees emphasizing that "we are trying to improve our energy efficiency and our energy use and from my understanding this is linked to CE'. Those practices were described as having the potential to improve the efficiency of existing infrastructures thus reducing the consumption of resources (e.g. water, energy — for lighting, energy — for cooling/heating, emissions and waste) and therefore resulting in the reduction of the environmental impacts of the organisations' activities. This category of practices can be associated to one of the basic principles of $\mathrm{CE}$ that is to narrow resource and energy loops corresponding to improvements where fewer resources are used in operations and organisational activities [64]. Previously researched in the context of private companies and the manufacturing industry $[4,65]$, the optimisation dimension of $\mathrm{CE}$ is shown here to be an important aspect of $\mathrm{CE}$ for a central public sector context. 
The analysed documents and reports did not contain any additional optimisation practices as indicated in Table 3, except for adopting water efficiency practices and implement EMSs for certifications. This might be because resource efficiency-related measures such as infrastructure upgrades are not new practices and usually undertaken for financial reasons rather than under the sustainability realm [36].

Some interviewees stated that PSOs must consider the consumption or usage aspects of products and infrastructure when deciding on which practice to implement in the organisation. Consumption-related considerations can be associated to the debate around the risks of rebound effects put forward by CE researchers questioning whether optimisation practices truly result in increased circularity if more efficiency might give way to more consumption (e.g. [66]). Remarks made during the interviews seem in line with the literature that has also criticized optimisation practices to only bring incremental change and improvements [17, 41]. The implementation of CE in PSOs is characterised so far by initiatives limited in scope of change, solely oriented towards energy and resource efficiency and mere waste reduction $[34,36]$.

In addition, the practice of using buildings or office spaces for optimal purposes was pointed out as a CE practice for central PSOs by a couple of interviewees. Indeed, central PSOs in Portugal are mainly located in the capital city of Lisbon and have their offices in old buildings (including several historical buildings with strict rules of use) which require significant maintenance works in resource and energy efficiency but other efficiency practices might include changes in the use of certain spaces and buildings, and thus could even involve the relocation of PSOs as one of the interviewees pointed out with the following statement: 'I think the change of locations. These buildings could have another utilisation that could be better than an office building'. It is an interesting practice that is raised here as there is a lack of studies looking at how to evaluate the best use of a central public building or public administration indoor space. However, research has been done on cultural heritage buildings proposing evaluation frameworks to adaptively reuse underutilised or abandoned buildings [67, 68].

Interviewees and a report from the defence sector [69] have mentioned that if the organisation is certified with an EMS such as ISO:14001 and EMAS or a quality standard (e.g. ISO:9001), it implies that the organisation has gone through a number of organisational changes related to resource efficiency and optimisation, and awareness raising of employees on environmental and sustainability issues, integrating several $\mathrm{CE}$ related principles and practices. Indeed, implementing an EMS or a sustainability management system (e.g. ISO: 20121 for sustainable events) in a PSO has been acknowledged to have benefits in terms of reduced carbon emissions, reduced waste and improved overall performance, including enhanced operational and administration efficiencies saving energy, other resources and financial costs [70], which are in line with CE principles [34].

Table 3 Optimisation practices mentioned by the interviewees and indicated in the documents

\begin{tabular}{lll}
\hline Optimisation Practices & $\begin{array}{l}\text { From the } \\
\text { interviews }\end{array}$ & $\begin{array}{l}\text { From the } \\
\text { documents }\end{array}$ \\
\hline Adopt water efficiency practices & $\mathrm{X}$ & $\mathrm{X}$ \\
Implement LED lighting system & $\mathrm{X}$ & \\
Install insulated double glass windows & $\mathrm{X}$ & \\
Implement centralized air-conditioning management & $\mathrm{X}$ & $\mathrm{X}$ \\
Use all building spaces for optimal purposes & $\mathrm{X}$ & \\
Implement measures in compliance with standards such as ISOs and & $\mathrm{X}$ \\
\multicolumn{1}{l}{ EMAS } & & \\
\hline
\end{tabular}




\section{R-Based and Sharing Practices}

Although the optimisation of infrastructure contributes to resource use reduction, the results show that other $\mathrm{CE}$ practices have been perceived by the interviewees as suitable in the context of reducing or avoiding the use of resources, especially non-renewable resources such as plastics and fossil fuel-based energy. As an employee mentioned: 'With what we can do here, it's about reducing the use of materials like disposable materials. We need some in hospitals but not here in our service offices (...). So, we want to end the disposable products'. This quote is an example demonstrating that the majority of R-based practices identified aim to reduce, refuse and ultimately eliminate single-use plastics items in PSOs. Those practices were perceived as incentivising individuals to refuse disposable products and to encourage reusing or using longer more sustainable alternatives, thus contributing to reduce the use of disposable single-use plastic items. Previous literature has highlighted similar CE practices being implemented such as the provision of reusable mugs to students and employees [34]. In the context of the Portuguese case study, this focus on reduce and reuse is probably due to the fact that in 2018 the Portuguese Council of Ministers approved a resolution with measures aiming at promoting the sustainable use of resources and the adoption of circular solutions in public administration, specifically promoting the reduction of paper consumption, other printing consumables and plastic products [71] $]^{1}$. Consequently, providing reusable cups and glass bottles to employees and visitors, and having vending machines offering a price preference when using a reusable cup are examples of reduce and reuse practices that have been mentioned recurrently in the interviews and are present in the analysed documents (see Table 4), with recommendations for instance for meetings and events to favour the use of tap water using reusable jugs and cups, or the use of reusable products such as plates, cutlery and glasses for catering services.

Moreover, compared to CE practices in the context of a private company manufacturing products, a PSO is an organisational system of employees working together to deliver a public service or developing policies and regulations among other things. Therefore, CE practices that are found in the business sector such as remanufacture, refurbish or eco-design practices are, in most cases, not suitable practices for the majority of the PSOs and therefore have not been mentioned by the interviewees. The Rs practices that emerge from this central public sector case show that $\mathrm{CE}$ implementation in the public sector at organisational level should be considered from a consumer-oriented perspective [14] with R-based practices including refuse, reduce, reuse, repair and recycle.

Although primarily considered as a socially based dimension of CE by some authors [45], sharing practices have been included in this R-based practices section as they enable both the reuse and more intensive use of products and equipment [48, 49]. A few interviewees mentioned the existence of, or interest in having, a platform where people within and in between public entities could share products and equipment such as electrical and electronic equipment for optimal and extended use. The use of a platform to share medical equipment and to share intangible human-based resources such as skills and capabilities for repair for instance was indicated in the analysed documents. Indeed, the use of digital government platforms has been suggested by Ganapati and Reddick [48] as a means to share, lease or rent assets on demand. They argue that PSOs can for instance reduce the large inventories of owned assets that are not fully used. The shared use of cars for mobility was neither mentioned

${ }^{1}$ The resolution is one of the analysed documents in the study. 
Table 4 R-based and sharing practices mentioned by interviewees and indicated in the documents.

\begin{tabular}{|c|c|c|c|}
\hline Rs categories & Practices & $\begin{array}{l}\text { From the } \\
\text { interviews }\end{array}$ & $\begin{array}{l}\text { From the } \\
\text { documents }\end{array}$ \\
\hline \multirow[t]{3}{*}{ Refuse/reduce/reuse } & Install vending machines allowing reusable containers & $\mathrm{X}$ & $\mathrm{X}$ \\
\hline & Provide reusable cups and bottles to employees and visitors & $\mathrm{X}$ & $\mathrm{X}$ \\
\hline & $\begin{array}{l}\text { Favour the use of reusable products over disposable products } \\
\text { for day-to-day work, meetings, events and for communica- } \\
\text { tion and promotional purposes }\end{array}$ & $\mathrm{X}$ & $\mathrm{X}$ \\
\hline \multirow[t]{2}{*}{ Sharing/reuse } & $\begin{array}{l}\text { Implement sharing platforms to extend the life-use of products, } \\
\text { equipment and furniture within and between services and } \\
\text { entities }\end{array}$ & $\mathrm{X}$ & $\mathrm{X}$ \\
\hline & $\begin{array}{l}\text { Donate products, materials and food surpluses internally and } \\
\text { externally to social entities }\end{array}$ & & $\mathrm{X}$ \\
\hline Repair & Provide repair services & $\mathrm{X}$ & $\mathrm{X}$ \\
\hline Recycle & $\begin{array}{l}\text { Install separated waste collection system of containers for } \\
\text { recycling }\end{array}$ & $\mathrm{X}$ & $\mathrm{X}$ \\
\hline
\end{tabular}

by the interviewees nor in the documents and reports although it is a sharing practice that has received attention in the literature as a valued practice within a CE [49]. In addition, donating products, equipment and food surpluses to other public entities or to social entities was also mentioned in the documents but not highlighted by any interviewee. The practice of donating can be situated in a realm of the CE (reuse principle) and sharing economy (via the gift economy) [45] as an act of giving an otherwise idle resource to other PSOs or charities in order to ensure the use or consumption of the resource and prevent it from being wasted.

The reuse practice is generally characterised by a second person taking over something from the original owner without any modifications to it; i.e. there can be a monetary transaction marking the change in ownership (e.g. buying second-hand) [14], or this may be a non-monetary transaction in the sharing sense [49]. For the public sector, reuse can fit into the sharing economy through practicing the shared use of resources with no monetary exchange using digital government platforms or through the development of procurement contracts that includes renting products, equipment or services from other public or private organisations. This discussion shows the difficulty in clearly defining the $\mathrm{CE}$ in its practices and multiple dimensions [14], and it highlights the importance of considering the specific operational conditions and opportunities for central PSOs in identifying and developing CE practices and shift towards a better circular resource management, improving organisational sustainability performance.

An interviewee also mentioned that having repair services available to fix equipment in some public administration entities would be useful, but also claimed that it might not be feasible due to a lack of human resources. In addition, a report indicated the existence of centralized services for medical equipment repair [72]. Finally, regarding the lower levels of R-based practices, interviewees and documents have also consistently highlighted the importance of a waste separation collection system thus showing that recycling practices in central PSOs are perceived as wellestablished CE practices, as also pointed out by Barreiro-Gen and Lozano [7].

\section{Dematerialisation Practices}

The dematerialisation of administrative processes and the adoption of digital government platforms have been seen by the interviewees as suitable CE practices and also 
highlighted in the documents with clear recommendations to switch to virtual operations such as the use electronic notifications, digital signatures and receipts. The majority of the dematerialising practices emerging from the interviews and present in the documents were related to paper consumption and printing consumables (see Table 5). One reason for this emphasis is because of the ministerial resolution on the adoption of circular solutions in public administration for paper and plastic, promoting process optimisation and the modernisation of administrative procedures [71]. Transitioning to digital government procedures and information flows was seen as important to improve the effectiveness and adaptability of public administration. However, interviewees also highlighted the challenges for employees to change habits and shift to digital-based operations, with statements such as 'I know digitalisation is important but I print and I know that I shouldn't print' and 'People are used to printing a page or something. I think from time to time culture is difficult, people still have the attitude of printing emails'. They pointed out that in their organisations, people are slowly starting to abandon the use of paper by using the digital platforms and computer hardware tools for daily work, meeting and events. Dematerialising administrative procedures in the public sector is a significant trend internationally. Although the initiatives emerged as an effort to simplify and make more efficient public administration processes and services $[15,73]$, these organisational changes can be seen as CE practices as they have the potential to increase the efficiency of resource use and help to minimise waste and consumption of resources [52].

Additionally, a couple of interviewees have argued that having more virtual, online meetings and teleconferences is a relevant practice pertaining to $\mathrm{CE}$ as it would contribute to the reduction and more efficient use of resources (e.g. floor space), lowering the financial and time costs of travelling, the associated environmental costs and social impacts. This virtualisation practice can be found in the literature for instance as virtual travel in a $\mathrm{CE}$ framework for mobility created by the EMF [74]. Such sustainability benefits have been mentioned in the literature especially in terms of effects on energy consumption for transportation $[75,76]$. Teleworking has also been mentioned by interviewees and is likely to become a common practice to implement in PSOs as a safety measure in the context of increasing health crises that generate sustainability-related effects [77]. Neither practice was found in the documents and reports.

Table 5 Dematerialisation practices mentioned by the interviewees and indicated in the documents

\begin{tabular}{|c|c|c|}
\hline Dematerialisation Practices & $\begin{array}{l}\text { From the } \\
\text { interviews }\end{array}$ & $\begin{array}{l}\text { From the } \\
\text { documents }\end{array}$ \\
\hline $\begin{array}{l}\text { Implement interoperable digital document management system for internal and } \\
\text { external procedures and communication including e.g. electronic } \\
\text { notification systems, electronic signature, receipts and smart documents }\end{array}$ & $\mathrm{X}$ & $\mathrm{X}$ \\
\hline $\begin{array}{l}\text { Favour the use of digital platforms and computer hardware tools for day-to-day } \\
\text { work, meetings and events }\end{array}$ & $\mathrm{X}$ & $\mathrm{X}$ \\
\hline Favour the use of emails over paper mailing & & $\mathrm{X}$ \\
\hline $\begin{array}{l}\text { Scan/Digitise paper documents intended for digital archiving and transfer into } \\
\text { electronic files }\end{array}$ & & $\mathrm{X}$ \\
\hline Implement a tracking system and quotas for copy printing & $\mathrm{X}$ & $\mathrm{X}$ \\
\hline Organise virtual online meetings (e.g. e-meetings, teleconferences) & $\mathrm{X}$ & \\
\hline Adopt teleworking and working from home & $\mathrm{X}$ & \\
\hline
\end{tabular}




\section{Circular Public Procurement}

Using PP to promote sustainable production and consumption has been recognized as potentially one of the most powerful tools of the public sector $[32,78]$. This recognition is found in the results as several interviewees have highlighted the importance of the financial or acquisition department in PSOs, having the biggest impact by responsibly procuring goods and services for the functions of the public sector. Moreover, the fact that the highest number of CE practices is in the PP procedures highlights the specificity of the public sector to leverage its purchasing power to promote and encourage $\mathrm{CE}$ implementation in the other sectors of society [25]. The majority of the CPP practices, as outlined in Table 6, have also been identified in the governmental reports and legislative documents. PP is a significant part of PSOs where CE principles can be adapted as criteria or specification for the purchase of products or equipment. Therefore, to give an overview of the range of CE principles that could be translated as criteria or practices for $\mathrm{PP}$, the first column in Table 6 was added to categorize the criteria or practices identified.

Most of the purchasing practices mentioned consist of integrating R-based criteria in the development of tenders related to the shorter loops closing practices, such as

Table 6 Circular public procurement practices and criteria mentioned by the interviewees and indicated in the documents

\begin{tabular}{|c|c|c|c|}
\hline CE categories & Practices and Criteria & $\begin{array}{l}\text { From the } \\
\text { interviews }\end{array}$ & $\begin{array}{l}\text { From the } \\
\text { documents }\end{array}$ \\
\hline \multirow[t]{2}{*}{ Optimisation } & Criteria of certified suppliers for developing tenders & $\mathrm{X}$ & \\
\hline & $\begin{array}{l}\text { Criteria for the supply of certified products with labels (e.g. EU } \\
\text { ecolabel) that meet the vast majority of repairability, reuse and } \\
\text { recycling requirements }\end{array}$ & $\mathrm{X}$ & $\mathrm{X}$ \\
\hline Refuse & $\begin{array}{l}\text { Clause prohibiting the purchase and use of single-use or disposable } \\
\text { plastic products }\end{array}$ & $\mathrm{X}$ & $\mathrm{X}$ \\
\hline $\begin{array}{l}\text { Material } \\
\quad \text { substitution }\end{array}$ & Criteria for the provision of a minimum level of renewable energy & $\mathrm{X}$ & \\
\hline $\begin{array}{l}\text { Material } \\
\quad \text { substitution }\end{array}$ & Criteria to replace the car fleet with electric vehicles & $\mathrm{X}$ & $\mathrm{X}$ \\
\hline Reduce & $\begin{array}{l}\text { Criteria for the supply of bulk products or products with reduced } \\
\text { amount of plastic packaging if plastic packaging is unavoidable }\end{array}$ & $\mathrm{X}$ & $\mathrm{X}$ \\
\hline Reuse/repair & $\begin{array}{l}\text { Criteria for the supply of reused, repairable, reusable products or of } \\
\text { products containing recycled material (e.g. recycled paper) }\end{array}$ & $\mathrm{X}$ & $\mathrm{X}$ \\
\hline Repair/recycle & $\begin{array}{l}\text { Criteria for the supply of products with a return guarantee on the } \\
\text { products supplied and take back system of related waste }\end{array}$ & & $\mathrm{X}$ \\
\hline Recycle & $\begin{array}{l}\text { Obligation to comply with the regime of waste management } \\
\text { operations for construction and demolition of buildings including } \\
\text { recycling and recovery of materials in public works contracts }\end{array}$ & & $\mathrm{X}$ \\
\hline \multirow[t]{2}{*}{ Functionality } & $\begin{array}{l}\text { Procedures for the leasing of printers, electrical and electronic } \\
\text { equipment, textiles, furniture and motor vehicles with obligation } \\
\text { to repair to enable reuse }\end{array}$ & $\mathrm{X}$ & $\mathrm{X}$ \\
\hline & $\begin{array}{l}\text { Criteria of pay-per-use printing system, low energy consuming and } \\
\text { connected printers in developing tenders }\end{array}$ & $\mathrm{X}$ & $\mathrm{X}$ \\
\hline Last resort & $\begin{array}{l}\text { Clause to include, in the impossibility of avoiding plastic products, } \\
\text { favouring the supply of certain plastic products that meet the } \\
\text { largest number of criteria for safety, among others. }\end{array}$ & & $\mathrm{X}$ \\
\hline
\end{tabular}


refuse, reduce, reuse and repair. The criterion of prohibiting the purchase of singleuse disposable plastic products was identified which can be referred to the most desirable-based option of refusing products made of unsustainable material. Additionally, the criteria encouraging the procurement of reused, reusable and repaired products or made of recycled material have been recommended, as well as the procurement of products with the minimum of plastic packaging. As shown in Table 6, the documents have also mentioned criteria addressing the end-of-life of products, such as the requirement of providing products with a take back system and a criterion regarding public works contracts in which the recycling and recovery of construction and demolition materials must be tackled. CPP criteria covering most of the R-based options for circular products show that the interviewees' perceptions, and the documents provided seem in line with conclusions made in Klein et al.'s [8] study, demonstrating that the most common CPP practices both in practice and in the literature appear to be the integration of criteria for remanufactured or reused products (such as computers and office furniture) and for recycled content in products (such as for construction of public buildings).

In addition to those R-based PP criteria, requesting the selected suppliers and products to be certified has been another criteria highlighted by a respondent working on PP. Incorporating requirements related to certifications, such as ISO standards and EMAS or ecolabels for products and services, ensures that suppliers and products comply to the environmental and associated quality standards. Furthermore, the interviewees stated that it helps the procurers to have a guarantee on the minimum standards in the suppliers' value chain and during the product's life cycle. An interviewee working with PP added to this point that 'we cannot control the way suppliers produce and do it at the end but if they comply to some standards, it's not up to us to control whether they are complying or not. There are other entities that are following up for these certifications. So, the most we can do in that case is to make sure that those suppliers are certified with those standards'. The use of standard certifications and ecolabels has been pointed out as useful sustainable consumption tools to use as a criteria to promote the production of products and services [79-81] as well as for public services [82].

Procuring functionality was also referred to in the analysed documents and by a couple of interviewees. Examples include adopting PP procedures to create contracts based on the use of products as a service (e.g. printing or lighting as a service) leaving the ownership of the products to the supplier that can repair and resell the products and extend their life span. Most of the CPP criteria brought up by the interviewees were mainly mentioned for the procurement of printers, whereas literature has focused rather on computers as ICT products [30, 81].

All in all, this section has shown that the interviewees tend to first mention resource efficiency and optimisation practices, especially related to infrastructure and energy efficiency. It has been observed that the interviewees also discussed sharing and dematerialising practices namely focusing on consumption reduction and reuse of plastic-based products and paper. Finally, the biggest area of CE practices as highlighted by the interviewees was CPP covering all aspects of CE ranging from purchasing optimized and efficient products to procuring functionality and performance. 


\section{Conclusions}

This paper identified and discussed a set of CE practices for central PSOs by conducting semistructured interviews with selected employees from the Portuguese Central Public Administration (PCPA) and by analysing complementary governmental reports and legislative documents. The interviewees mentioned CE implementation as a diverse array of practices related to resource efficiency and optimisation, R-based principles such as reduce and reuse, sharing economy and dematerialisation and emphasized in particular the practices related to CPP. This study has shown that both technical-oriented practices aiming towards traditional resource efficiency and human/social-centred practices targeted to consumption reduction and sharing activities are relevant CE practices according the interviewed employees. The article therefore demonstrates that central public sector employees in Portugal are aware of the transformative potential of introducing CE practices that include circular-oriented consumption behaviours in day-to-day operations alongside the traditional technical resource efficiency-oriented organisational practices.

The research done here is one of the first empirical studies providing insights into how a specific group of public stakeholders, which are public employees, perceive CE implementation for their specific sector and organisations. Asking internal stakeholders such as employees for their view of the most suitable and relevant $\mathrm{CE}$ practices for the central public sector contributes to support decision-makers in the process of defining priority areas for $\mathrm{CE}$ planning, implementation and monitoring at organisational level.

Research on CE in the public sector at organisational level is in its infancy. There is a significant potential to engage in stakeholder involvement methodologies in order to accelerate the transition to a CE. This research provides new knowledge and insights into what kind of practices are suitable to implement in the public sector at organisational level, particularly in the areas of PP and internal operations and processes. These are the areas in which practices impact directly on the circularity of resources in PSOs and therefore further research is recommended to investigate what types of strategies are needed in addition to the proposed $\mathrm{CE}$ practices that contribute indirectly to the uptake and integration in the long term of circularity in the public sector. Several gaps in the research have been highlighted such as the need for impact assessment studies of dematerialisation and building efficiency in a CE context. Further research is also needed looking at case studies of central government in other countries than Portugal as well as at the views of other groups of stakeholders such as suppliers. There is likewise a need to examine different levels of government such as the regional or local/municipal level initiatives for perspectives on organisational public sector circularity.

\section{Appendix 1. Interview Protocol}

\section{Introduction}

- Which organisation do you work for?

- What is the purpose of your organisation?/What is your organisation doing? 
- Are you engaged in sustainability/environmental/CE related activities in your organisation?

- What is your role in the organisation?

\section{Circular economy in general}

According to you:

- How would you define $\mathrm{CE}$ and is it considered an important topic in your organisation?

- What is the potential of implementing CE for your organisation?

- What is your organisation's contribution to CE?

\section{Circular economy practices}

\section{Current practices and activities within the organisation}

According to you:

- What are the main resources streams (in material terms such as water, waste, paper, plastic) and energy sources that your organisation is currently managing/working on to advance $\mathrm{CE}$ in the organisation (in a circular way)?

- What about any services (immaterial resources) that you need in addition to material resources that you are aligning with CE?

- Do you have any practices/activities at operational (e.g. related to waste, energy, transport, water, paper, plastic, sharing, etc.) related to $\mathrm{CE}$ within your organisation?

- Do you have any actions/commitments at strategic level (e.g. policies, regulations, plans, programmes) related to $\mathrm{CE}$ for your organisation?

\section{Recommended practices to be implemented}

According to you:

- What are the practices/activities that you think need to be taken into account in the future (e.g. related to waste, energy, transport, water, paper, plastic, sharing, etc.) to incorporate $\mathrm{CE}$ within your organisation?

- Going into more specifics, do you consider that there are different aspects/parts of the organisation that are important in regard to CE? If yes, what are they?

- Does your organisation do anything in particular regarding implementing $\mathrm{CE}$ in those parts of the organisation that you mention? 


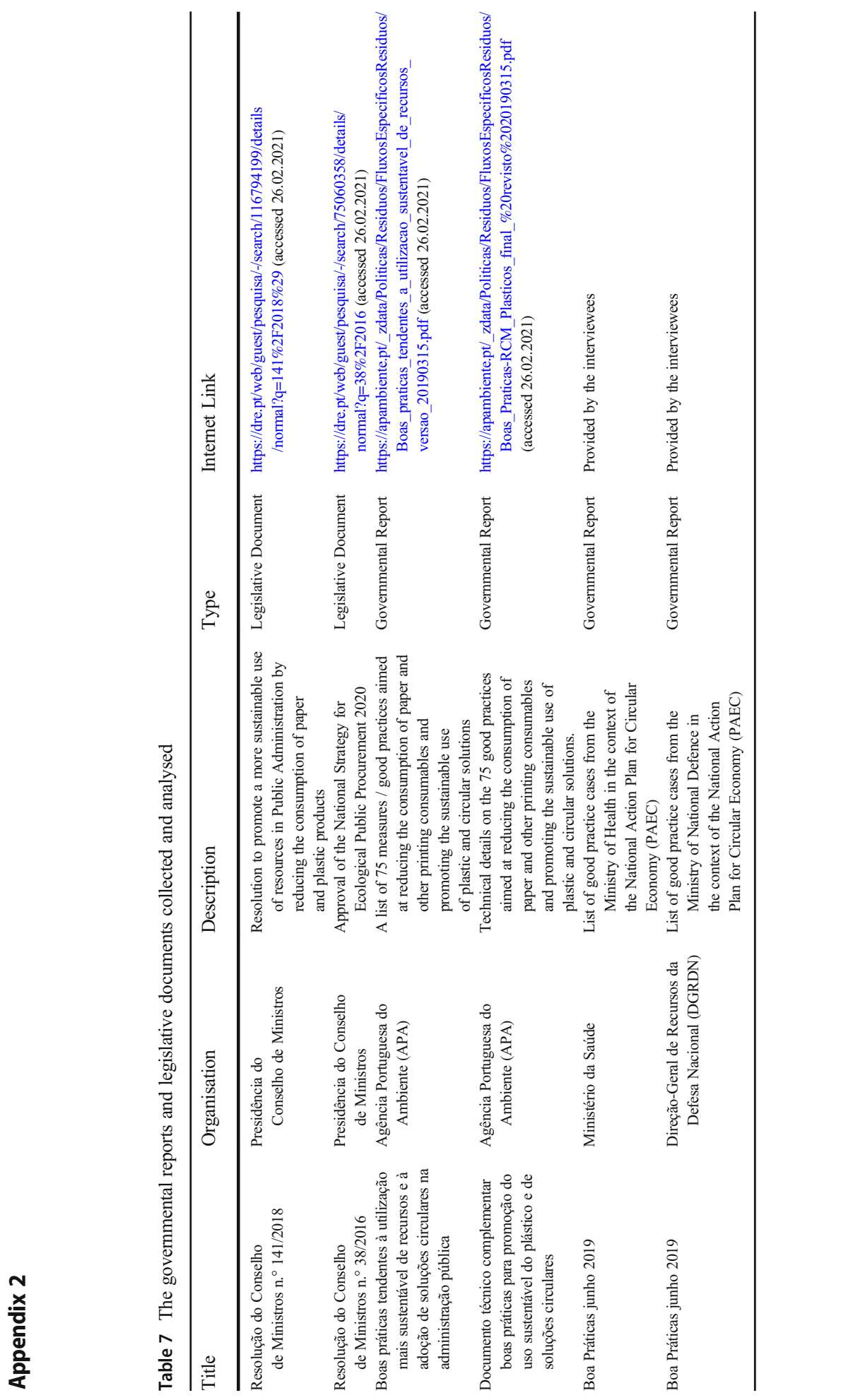


Acknowledgements Previous versions of this work were presented at the Publication for Early Researchers (PubliER) 2020 conference in Troyes, France on the 30th of January 2020 and at the 26th International Sustainable Development Research Society (ISDRS) Conference online on the 15th July 2020 hosted by Budapest University of Technology and Economics (BME). The authors would like to thank the interviewees, Reid Lifset for the thorough review and helpful suggestions for earlier versions of this paper as well as the reviewers for their constructive comments.

Author Contribution All authors contributed to the study conception and design. Material preparation, data collection and analysis were performed by Natacha Klein. The first draft of the manuscript was written by Natacha Klein, and all authors worked and commented on all versions of the manuscript. All the authors read and approved the final manuscript.

Funding This research received funding from the European Union's Horizon 2020 research and innovation programme under the Marie Skłodowska-Curie grant agreement No. 765198 and constitutes part of the outcomes of the research project CRESTING (Circular Economy: Sustainability implications and guiding progress). The authors received support given to CENSE by the Portuguese Foundation for Science and Technology (FCT) through the strategic project UIDB/04085/2020.

Data availability The data that support the findings of this study are available in aggregated form on request from the corresponding author. The data are not publicly available since they contain information that could compromise the privacy of research participants.

\section{Declarations}

Competing Interests The authors declare no competing interests.

Open Access This article is licensed under a Creative Commons Attribution 4.0 International License, which permits use, sharing, adaptation, distribution and reproduction in any medium or format, as long as you give appropriate credit to the original author(s) and the source, provide a link to the Creative Commons licence, and indicate if changes were made. The images or other third party material in this article are included in the article's Creative Commons licence, unless indicated otherwise in a credit line to the material. If material is not included in the article's Creative Commons licence and your intended use is not permitted by statutory regulation or exceeds the permitted use, you will need to obtain permission directly from the copyright holder. To view a copy of this licence, visit http://creativecommons.org/licenses/by/4.0/.

\section{References}

1. Geissdoerfer M, Morioka SN, de Carvalho MM, Evans S (2018) Business models and supply chains for the circular economy. J Clean Prod 190:712-721. https://doi.org/10.1016/j.jclepro.2018.04.159

2. Franco MA (2017) Circular economy at the micro level: a dynamic view of incumbents' struggles and challenges in the textile industry. J Clean Prod 168:833-845. https://doi.org/10.1016/j.jclepro.2017.09.056

3. Ghisellini P, Cialani C, Ulgiati S (2016) A review on circular economy: the expected transition to a balanced interplay of environmental and economic systems. J Clean Prod 114:11-32. https://doi.org/10.1016/j. jclepro.2015.09.007

4. Masi D, Kumar V, Garza-Reyes JA, Godsell J (2018) Towards a more circular economy: exploring the awareness, practices, and barriers from a focal firm perspective. Prod Plan Control 29:539-550. https://doi. org/10.1080/09537287.2018.1449246

5. Merli R, Preziosi M, Acampora A (2018) How do scholars approach the circular economy? A systematic literature review. J Clean Prod 178:703-722. https://doi.org/10.1016/j.jclepro.2017.12.112

6. EMF (2013) Towards a circular economy: economic and business rationale for an accelerated transition, Ellen MacArthur Foundation. https://www.ellenmacarthurfoundation.org/assets/downloads/publications/ Ellen-MacArthur-Foundation-Towards-the-Circular-Economy-vol.1.pdf. Accessed 22 Mar 2021 
7. Barreiro-Gen M, Lozano R (2020) How circular is the circular economy? Analysing the implementation of circular economy in organisations. Bus Strateg Environ 29:1-11. https://doi.org/10.1002/bse.2590

8. Klein N, Ramos TB, Deutz P (2020) Circular economy practices and strategies in public sector organizations: an integrative review. Sustain 12:23. https://doi.org/10.3390/su12104181

9. Ten Wolde A (2016) Briefing: Governments as driver for a circular economy. Waste Resour Manag 169: 149-150. https://doi.org/10.1680/jwarm.16.00017

10. De Groene Zaak (2015) Governments going circular. http://www.govsgocircular.com/media/1354/ governments-going-circular-dgz-feb2015.pdf. Accessed 22 Mar 2021

11. Global Reporting Initiative (2005) Sector Supplement for Public Sector Agencies: Pilot Version 1.0. GRI: Amsterdam, NL

12. UNEP (2018) Building circularity into our economies through sustainable procurement. https://wedocs. unep.org/bitstream/handle/20.500.11822/26599/circularity procurement.pdf?isAllowed=y\&sequence=1. Accessed 22 Mar 2021

13. Eurostat (2019) Government expenditure by function - COFOG. https://ec.europa.eu/eurostat/statisticsexplained/index.php/Government_expenditure_by_function_-_COFOG. Accessed 22 Apr 2020

14. Reike D, Vermeulen WJV, Witjes S (2018) The circular economy: new or refurbished as CE 3.0? exploring controversies in the conceptualization of the circular economy through a focus on history and resource value retention options. Resour Conserv Recycl 135:246-264. https://doi.org/10.1016/j.resconrec. 2017.08.027

15. Figueira I, Domingues AR, Caeiro S, Painho M, Antunes P, Santos R, Videira N, Walker RM, Huisingh D, Ramos TB (2018) Sustainability policies and practices in public sector organisations : the case of the Portuguese Central Public Administration. J Clean Prod 202:616-630. https://doi.org/10.1016/j.jclepro. 2018.07.244

16. Ranängen H, Cöster M, Isaksson R, Garvare R (2018) From global goals and planetary boundaries to public governance-a framework for prioritizing organizational sustainability activities. Sustain 10 . https://oi.org/ $10.3390 / \mathrm{su} 10082741$

17. Kirchherr J, Reike D, Hekkert M (2017) Conceptualizing the circular economy: an analysis of 114 definitions. Resour Conserv Recycl 127:221-232. https://doi.org/10.1016/j.resconrec.2017.09.005

18. Schulz C, Hjaltadóttir RE, Hild P (2019) Practising circles: studying institutional change and circular economy practices. J Clean Prod 237:117749. https://doi.org/10.1016/j.jclepro.2019.117749

19. Crane A, Matten D (2004) Business ethics, a European perspective: managing corporate citizenship and sustainability in the age of globalization. Oxford University Press, Oxford

20. Coutinho V, Domingues AR, Caeiro S, Painho M, Antunes P, Santos R, Videira N, Walker RM, Huisingh D, Ramos TB (2018) Employee-driven sustainability performance assessment in public organisations. Corp Soc Responsib Environ Manag 25:29-46. https://doi.org/10.1002/csr.1438

21. Chiappetta Jabbour CJ, Sarkis J, Lopes de Sousa Jabbour AB et al (2019) Who is in charge? A review and a research agenda on the 'human side' of the circular economy. J Clean Prod 222:793-801. https://doi.org/10. 1016/j.jclepro.2019.03.038

22. Hobson K (2019) 'Small stories of closing loops': social circularity and the everyday circular economy. Clim Chang 163:99-116. https://doi.org/10.1007/s10584-019-02480-Z

23. Yuan Z, Bi J, Moriguichi Y (2006) The circular economy: a new developement strategy in China. J Ind Ecol 10:4-8. https://doi.org/10.1038/531435a

24. Liu Q, Li H m, Zuo X 1 et al (2009) A survey and analysis on public awareness and performance for promoting circular economy in China: a case study from Tianjin. J Clean Prod 17:265-270. https://doi.org/ 10.1016/j.jclepro.2008.06.003

25. Alhola K, Ryding S-O, Salmenperä H, Busch NJ (2018) Exploiting the potential of public procurement: opportunities for circular economy. J Ind Ecol 23:96-109. https://doi.org/10.1111/jiec.12770

26. EC (2017) Public Procurement for a circular economy: good practices and guidance. http://ec.europa.eu/ environment/gpp/pdf/Public_procurement_circular_economy_brochure.pdf. Accessed 22 Mar 2021

27. Witjes S, Lozano R (2016) Towards a more circular economy: proposing a framework linking sustainable public procurement and sustainable business models. Resour Conserv Recycl 112:37-44. https://doi.org/10. 1016/j.resconrec.2016.04.015

28. Gelderman CJ, Semeijn J, Vluggen R (2017) Development of sustainability in public sector procurement. Public Money Manag 37:435-442. https://doi.org/10.1080/09540962.2017.1344027

29. Rainville A (2018) Standards in green public procurement - a framework to enhance innovation. J Clean Prod 167:1029-1037. https://doi.org/10.1016/j.jclepro.2016.10.088

30. Crafoord K, Dalhammar C, Milios L (2018) The use of public procurement to incentivize longer lifetime and remanufacturing of computers. Procedia CIRP 73:137-141. https://doi.org/10.1016/j.procir.2018.03. 316 
31. Ammenberg J, Anderberg S, Lönnqvist T, Grönkvist S, Sandberg T (2018) Biogas in the transport sectoractor and policy analysis focusing on the demand side in the Stockholm region. Resour Conserv Recycl 129:70-80. https://doi.org/10.1016/j.resconrec.2017.10.010

32. Stahel WR (2019) The circular economy - a user's guide. Routledge, London

33. Kristensen HS, Mosgaard MA, Remmen A (2020) Circular public procurement practices in Danish municipalities. J Clean Prod:124962. https://doi.org/10.1016/j.jclepro.2020.124962

34. Mendoza JMF, Gallego-Schmid A, Azapagic A (2019) Building a business case for implementation of circular economy in higher education institutions. J Clean Prod 220:553-567. https://doi.org/10.1016/j. jclepro.2019.02.045

35. Jones P, Comfort D (2018) Winning hearts and minds: a commentary on circular cities. J Public Aff 18:1-7. https://doi.org/10.1002/pa.1726

36. Nunes BT, Pollard SJT, Burgess PJ, Ellis G, de los Rios I, Charnley F (2018) University contributions to the circular economy: professing the hidden curriculum. Sustain 10:1-24. https://doi.org/10.3390/su10082719

37. Mendoza JMF, Gallego-Schmid A, Azapagic A (2019) A methodological framework for the implementation of circular economy thinking in higher education institutions: towards sustainable campus management. J Clean Prod 226:831-844. https://doi.org/10.1016/j.jclepro.2019.04.060

38. Marrucci L, Daddi T, Iraldo F (2019) The integration of circular economy with sustainable consumption and production tools: systematic review and future research agenda. J Clean Prod 240:118268. https://doi.org/ 10.1016/j.jclepro.2019.118268

39. Daddi T, De Giacomo MR, Frey M, Iraldo F (2018) Analysing the causes of environmental management and audit scheme (EMAS) decrease in Europe. J Environ Plan Manag 61:2358-2377. https://doi.org/10. 1080/09640568.2017.1395316

40. Fonseca LM, Domingues JP, Pereira MT, Martins F, Zimon D (2018) Assessment of circular economy within Portuguese organizations. Sustain 10:1-24. https://doi.org/10.3390/su10072521

41. Hobson K (2016) Closing the loop or squaring the circle? Locating generative spaces for the circular economy. Prog Hum Geogr 40:88-104. https://doi.org/10.1177/0309132514566342

42. Deutz P, Ioppolo G (2015) From theory to practice: enhancing the potential policy impact of industrial ecology. Sustain 7:2259-2273. https://doi.org/10.3390/su7022259

43. Erkman S (1997) Ecology : an historical view. J Clean Prod 5:1-10. https://doi.org/10.1016/S09596526(97)00003-6

44. Saavedra YMB, Iritani DR, Pavan ALR, Ometto AR (2018) Theoretical contribution of industrial ecology to circular economy. J Clean Prod 170:1514-1522. https://doi.org/10.1016/j.jclepro.2017.09.260

45. Hobson K, Lynch N (2016) Diversifying and de-growing the circular economy: radical social transformation in a resource-scarce world. Futures 82:15-25. https://doi.org/10.1016/j.futures.2016.05.012

46. Moreau V, Sahakian M, van Griethuysen P, Vuille F (2017) Coming full circle: why social and institutional dimensions matter for the circular economy. J Ind Ecol 21:497-506. https://doi.org/10.1111/jiec.12598

47. Henry M, Schraven D, Bocken N, Frenken K, Hekkert M, Kirchherr J (2021) The battle of the buzzwords: a comparative review of the circular economy and the sharing economy concepts. Environ Innov Soc Transitions 38:1-21. https://doi.org/10.1016/j.eist.2020.10.008

48. Ganapati S, Reddick CG (2018) Prospects and challenges of sharing economy for the public sector. Gov Inf Q 35:77-87. https://doi.org/10.1016/j.giq.2018.01.001

49. Schwanholz J, Leipold S (2020) Sharing for a circular economy An analysis of digital sharing platforms' principles and business models? J Clean Prod:122327. https://doi.org/10.1016/j.jclepro.2020.122327

50. EMF (2015) Delivering the circular economy: a toolkit for policymakers. Cowes, Ellen MacArthur Foundation

51. WBCSD (2020) Dematerialization. In: Circ. Econ. Pract. Guid. https://www.ceguide.org/Strategies-andexamples/Make/Dematerialization. Accessed 19 Aug 2020

52. Antikainen M, Uusitalo T, Kivikytö-Reponen P (2018) Digitalisation as an enabler of circular economy. Procedia CIRP 73:45-49. https://doi.org/10.1016/j.procir.2018.04.027

53. Mirabella N, Rigamonti L, Scalbi S (2013) Life cycle assessment of Information and Communication Technology application: a case study of dematerialization in the Italian Public Administration. J Clean Prod 44:115-122. https://doi.org/10.1016/j.jclepro.2012.10.051

54. Berkhout F, Hertin J (2004) De-materialising and re-materialising: digital technologies and the environment. Futures 36:903-920. https://doi.org/10.1016/j.futures.2004.01.003

55. Portuguese Ministry of Environment and Energy Transition (2017) Leading the transition: action plan for circular economy in Portugal: 2017-2020. https:/circulareconomy.europa.eu/platform/sites/default/files/ strategy_-_portuguese_action_plan_paec_en_version_3.pdf. Accessed 22 Mar 2021

56. OECD (2019) Government at a Glance 2019: Country Fact Sheet Portugal. http://www.oecd.org/gov/govat-a-glance-2019-portugal.pdf. Accessed 22 Mar 2021 
57. EC (2018) Public Administration characteristics and performance in EU 28: Portugal. In: The Public Administration in the EU 28. pp 816-844

58. Saunders M, Lewis P, Thornhill A (2016) Research methods for business students: seventh edition, 7th edn. Pearson, Harlow, Essex, England

59. Denscombe M (2010) The good research guide: for small-scale social research projects - fourth edition. Open University Press McGraw-Hill, Maidenhead, Berkshire, England

60. Flick U (2009) An introduction to qualitative research. SAGE Publications, Inc., Thousand Oaks

61. Bryman A (2012) Social research methods: 4th edition. Oxford University Press Inc., New York

62. Creswell JW (2014) Research design: qualitative, quantitative, and mixed methods approaches, 4th edn. SAGE Publications, Inc., Thousand Oaks

63. Berg BL (2001) Qualitative research methods for the social sciences. Allyn and Bacon, Needham Heights

64. Bocken NMP, de Pauw I, Bakker C, van der Grinten B (2016) Product design and business model strategies for a circular economy. J Ind Prod Eng 33:308-320. https://doi.org/10.1080/21681015.2016.1172124

65. Garcés-Ayerbe C, Rivera-Torres P, Suárez-Perales I, Hiz DILD La (2019) Is it possible to change from a linear to a circular economy? An overview of opportunities and barriers for European small and mediumsized enterprise companies. Int J Environ Res Public Health 16. https://doi.org/10.3390/ijerph16050851

66. Zink T, Geyer R (2017) Circular economy rebound. J Ind Ecol 21:593-602. https://doi.org/10.1111/jiec. 12545

67. Torrieri F, Fumo M, Sarnataro M, Ausiello G (2019) An integrated decision support system for the sustainable reuse of the former monastery of "Ritiro del Carmine" in Campania Region. Sustainability 11:5244. https://doi.org/10.3390/su11195244

68. Foster G (2020) Circular economy strategies for adaptive reuse of cultural heritage buildings to reduce environmental impacts. Resour Conserv Recycl 152:104507. https://doi.org/10.1016/j.resconrec.2019. 104507

69. DGRDN (2019) Boas Práticas (Junho 2019)

70. Zutshi A, Sohal AS, Adams C (2008) Environmental management system adoption by government departments/agencies. Int J Public Sect Manag 21:525-539. https://doi.org/10.1108/EL-01-2014-0022

71. PCM (2018) Resolução do Conselho de Ministros n. ${ }^{\circ}$ 141/2018

72. Ministério da Saúde (2019) Boas Práticas (Junho 2019)

73. Valdés G, Solar M, Astudillo H, Iribarren M, Concha G, Visconti M (2011) Conception, development and implementation of an e-Government maturity model in public agencies. Gov Inf Q 28:176-187. https://doi. org/10.1016/j.giq.2010.04.007

74. EMF, SUN, McKinsey (2015) Growth within: a circular economy vision for a competitive europe. https:// www.ellenmacarthurfoundation.org/assets/downloads/publications/EllenMacArthurFoundation_GrowthWithin_July15.pdf. Accessed 22 Mar 2021

75. van Lier T, de Witte A, Macharis C (2014) How worthwhile is teleworking from a sustainable mobility perspective? The case of Brussels Capital region. Eur J Transp Infrastruct Res 14:244-267. https://oi.org/ 10.18757/ejtir.2014.14.3.3033

76. Dima A-M, Tuclea C-E, Vrânceanu D-M, Tigu G (2019) Sustainable social and individual implications of telework : a new insight into the Romanian labor market. Sustain 11:1-12. https://doi.org/10.3390/ su11133506

77. Belzunegui-Eraso A, Erro-Garcés A (2020) Teleworking in the context of the Covid-19 crisis. Sustain 12:118. https://doi.org/10.3390/su12093662

78. Bratt C, Hallstedt S, Robèrt KH, Broman G, Oldmark J (2013) Assessment of criteria development for public procurement from a strategic sustainability perspective. J Clean Prod 52:309-316. https://doi.org/10. 1016/j.jclepro.2013.02.007

79. Prieto-Sandoval V, Mejía-Villa A, Ormazabal M, Jaca C (2019) Challenges for ecolabeling growth: lessons from the EU Ecolabel in Spain. Int J Life Cycle Assess 25:856-867. https://doi.org/10.1007/s11367-01901611-z

80. Dahl Sönnichsen S, Clement J (2020) Review of green and sustainable public procurement: towards circular public procurement. J Clean Prod 245:1-18. https://doi.org/10.1016/j.jclepro.2019.118901

81. Gåvertsson I, Milios L, Dalhammar C (2018) Quality Labelling for re-used ICT equipment to support consumer choice in the circular economy. J Consum Policy 43:353-377. https://doi.org/10.1007/s10603018-9397-9

82. Domingues AR, Moreno Pires S, Caeiro S, Ramos TB (2015) Defining criteria and indicators for a sustainability label of local public services. Ecol Indic 57:452-464. https://doi.org/10.1016/j.ecolind.2015. 05.016 


\section{Affiliations}

Natacha Klein ${ }^{1}$ - Tomás B. Ramos ${ }^{1}$ - Pauline Deutz ${ }^{2}$

1 CENSE-Center for Environmental and Sustainability Research, Department of Environmental Sciences and Engineering NOVA School of Science and Technology, NOVA University Lisbon, Lisbon, Portugal

2 Department of Geography, Geology and Environment, University of Hull, Hull, UK 